\title{
THE SAFETY AND EFFICACY OF TOPICAL NORFLOXACIN COMPARED WITH CHLORAMPHENICOL FOR THE TREATMENT OF EXTERNAL OCULAR BACTERIAL INFECTIONS
}

\author{
IAN M. MILLER, JOHANNA M. WITTREICH, THOMAS COOK, ROGER VOGEL FOR THE \\ NORFLOXACIN-CHLORAMPHENICOL OPHTHALMIC STUDY GROUP ${ }^{1}$ \\ West Point, Pennysylvania, USA
}

\begin{abstract}
SUMMARY
Two hundred and forty-six patients with signs of acute bacterial conjunctivitis and/or blepharitis were randomised to receive either norfloxacin or chloramphenicol for one week in this double-masked parallel group study. Ninety-two per cent of the norfloxacin-treated patients and $93 \%$ of the chloramphenicol-treated patients were rated as either clinically improved or cured at the end of the treatment period.

Based upon pre-treatment bacteriological cultures, $31.3 \%$ of the patients had significant bacterial infection of the lids and/or conjunctiva. All of these culture-positive patients were rated as either clinically improved or cured. Based upon post-treatment cultures, 72 of 82 strains of Gram-positive and Gram-negative bacteria were erradicated or suppressed following treatment with either norfloxacin or chloramphenicol. However six of $\mathbf{4 1}$ strains persisted for norfloxacin and four of $\mathbf{4 1}$ for chloramphenicol. Two norfloxacin-treated patients and three chloramphenicol-treated patients had adverse experiences, predominantly ocular discomfort, which required cessation of drug therapy.

Norfloxacin appears to be an effective and relatively safe agent for the treatment of bacterial infections of the lids and/or conjunctiva. In this study, norfloxacin was clinically and microbiologically similar in activity to chloramphenicol.
\end{abstract}

Bacterial infections of the conjunctiva and lids can be, at

From: Department of Ophthalmic Clinical Research, Merck \& Co.

'The Norfloxacin-Chloramphenicol Ophthalmic Study Group includes: Manuel Ober, Armin Scharrer (Fürth, Federal Republic of Germany); Peter Wright (Moorfields Eye Hospital, London); Andrew R. Elkington (Southampton Eye Hospital); Anthony J. Bron (Nuffield Laboratory of Ophthalmology, University of Oxford); Berit M. Calissendorf (Huddinge Hospital, Sweden); Dario W. C. Lorenzetti (Montreal General Hospital); Hannah Savir (Hasharon Hospital, Petach Tikvah, Israel); Yavul Yassur (Soroka Medical School, Beersheva, Israel); and David Seal (Glasgow, Scotland).

Correspondence to: Roger Vogel, M.D., Clinical Research, Merck, Sharp and Dohme Research Labs, West Point Pa 19436, USA. the very least, disquieting and bothersome, and more rarely result in sight-threatening complications. The ophthalmologist is limited by available antibacterial agents which may not be ideal due to limited antibacterial spectrum, the presence of resistance, or ocular or systemic side effects, (e.g. gentamicin). ${ }^{1}$ The quinolones are a new class of antibacterial drugs that provide broad-spectrum therapy applicable to ophthalmic infections. ${ }^{2}$ Quinolones inhibit bacterial DNA gyrase. This is a novel antibacterial mechanism, which is thought to be less likely to generate resistance. ${ }^{3}$

Norfloxacin is a quinolone derivative with a wide spectrum of antibacterial activity. Its spectrum covers Grampositive and Gram-negative bacteria, including Pseudomonas aeruginosa. ${ }^{3.4}$ Given orally, norfloxacin was effective for the treatment of adult gonococcal keratoconjunctivitis and without undesirable toxicity. ${ }^{5}$ In vitro, norfloxacin provides potent and wide spectrum antibacterial action ocular pathogens. ${ }^{6}$ Given the wide spectrum of activity, and positive systemic efficacy and safety profile, and the reduced likelihood for cross-resistance, we wished to evaluate the topical use of norfloxacin in treating infections of the conjunctiva and lids.

\section{SUBJECTS AND METHODS}

This was a randomised, double-masked, parallel-group comparison of $0.3 \%$ norfloxacin solution, preserved with $0.0025 \%$ benzalkonium chloride and commercially available $0.5 \%$ chloramphenicol, preserved with $0.002 \%$ phenylmercuric acetate (Chloromycetin ${ }^{\circledR}$, Parke-Davis). As commercially available chloramphenicol requires refrigeration, both treatments were refrigerated until dispensed to protect the masking of treatments.

For inclusion in the study, patients were required to have a clinical diagnosis of acute conjunctivitis or blepharoconjunctivitis. Patients with blepharitis were also admitted to the study, but only if the infection was acute. All 
patients were required to have conjunctival hyperemia, and at least one of the following: purulent exudates; crusting on eyelids; thickened, red lid margins; or loss of some cilia. Excluded were patients with: symptoms of longer than seven days duration; treatment with ophthalmic steroids or antibiotics in the previous two weeks; signs or symptoms suspected to be caused by a viral, chlamydial or fungal infection, or allergic inflammation; concomitant systemic antimicrobial therapy or other ophthalmic antimicrobial therapy; history of allergy to quinolone derivatives or to chloramphenicol; and women who were pregnant, nursing, or of childbearing potential and not using adequate contraceptive measures.

All patients gave informed consent. Prior to treatment, the investigators measured visual acuity, evaluated symptoms, and conducted an external ocular examination. A specimen for bacteriological evaluation was obtained from the conjunctiva (or lid margin for patients with blepharitis alone) with a moistened calcium alginate swab. The swab was placed in a Calgon-Ringer solution containing $1 \%$ sodium metaphosphate. At the bacteriology laboratory, the specimen was plated onto both blood and chocolate agar plates, and incubated for 48 hours in $4 \%$-enriched $\mathrm{CO}_{2}$. Both a qualitative and quantitative analysis of bacterial growth was performed, ${ }^{7,8}$ and the results expressed as colony forming units per $\mathrm{mL}$ of the Calgon-Ringer solution.

The prescribed regimen for the test drugs was one drop every two hours in the affected eye(s) during waking hours on the first day. On subsequent days, the regimen was one drop every four hours. Patients were required to return to the investigator after three full days of therapy. Patients with clinical improvement at this visit, irrespective of bacteriological results, continued the test medication for the balance of one week of therapy. These patients were requested to return for a final visit 12 to 72 hours after their final dose. Patients who did not show clinical improvement after three full days of therapy received treatment at the discretion of the investigator.

Patients were categorised on the basis of their pretreatment culture. To be considered positive, an organism must have been present in numbers greater than the critical number established for that type of culture. ${ }^{9}$ The critical numbers for the different organisms were: greater than 0 for Streptococcus pneumoniae, $\beta$-hemolytic streptococci, Neisseria sp., and all Gram-negative rods; 10 or greater for $\alpha$-hemolytic streptococci (other than S. pneumoniae), Staphylococcus aureus and Micrococcus sp.; 100 or greater for staphyloccus sp. and bacillus sp, and equal to or greater than 10,000 for corynebacteria. A bacteriological outcome was scored for each organism based on the bacterial counts obtained on the post-treatment swab. Cultures with no organisms present in the post-treatment swab were classified as erradicated; organisms present, but in lower numbers than the critical number were classified as suppressed; and organisms present in numbers equal to or greater than the critical number were classified as persisting.
Clinical outcome was scored at the end of therapy as cured (signs and symptoms of infection clear), improved (signs and/or symptoms still present but of less severity than at pretreatment), unimproved (no change in signs and symptoms from pretreatment), or worsened (signs and symptoms increased from pretreatment). To be considered evaluable, a patient was required to have a positive culture prior to treatment, and both a bacteriological and clinical outcome recorded.

Comparisons between treatment groups in bacteriological and clinical efficacy were performed using the Mantel-Haenszel procedure without continuity correction, stratifying on investigator. ${ }^{10,11}$ Treatment-by-investigator interaction was assessed by testing the homogeneity of the odds ratio. ${ }^{12}$ In those patients who received bilateral treatment, the eye with the worse clinical outcome was chosen for the analysis of clinical outcome. A similar, but separate selection was performed for bacteriological outcome. Demographic variables were compared between groups using an analysis of variance (age) or Fisher's exact test (categorical variables). For all comparisons, a critical value of $p$ value of $<=0.05$ was used.

\section{RESULTS}

Two hundred and forty-six patients were enrolled into the study. One hundred and sixty-nine of these patients had cultures with no organism isolated, insufficient organisms isolated, or did not have both pre-treatment and posttreatment cultures performed. These patients were considered non-evaluable for the analysis of bacteriological outcome.

As shown in Table I, the patients represented a large age range, including 13 patients under 18 years of age (nine in the norfloxacin group and four in the chloramphenicol group). There were more males in the norfloxacin treatment group, and more females in the chloramphenicol treatment group. This difference was statistically signifi-

Table I. Demographics and clinical characteristics

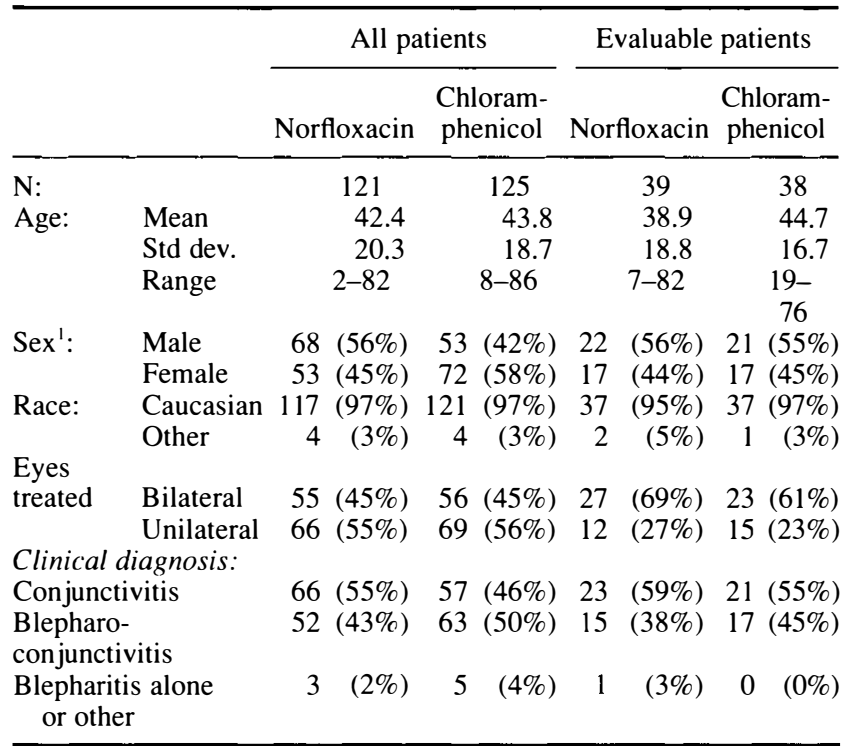

'Significant difference between treatment groups for all patients, $\mathrm{p}<0.05$. 
Table II. Clinical outcome (Confidence Intervals)

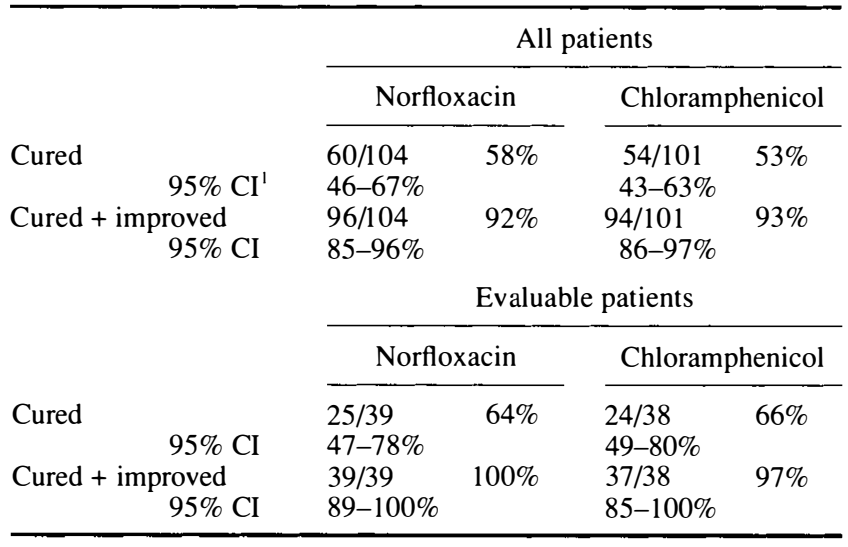

'Confidence interval.

cant. The patients were almost exclusively caucasian. Approximately half the patients received bilateral treatment, half had a diagnosis of conjunctivitis, and half the diagnosis of blepharoconjunctivitis. Only seven patients were admitted with acute blepharitis. Two patients, one with keratoconjunctivitis and one with a corneal ulcer, were not included in the analysis of efficacy.

The clinical outcome of treatment is shown in Table II. Irrespective of bacteriological status, most patients in both treatment groups were either clinically cured or improved. In the total study population, exclusive of those patients for whom no clinical outcome was available, $92 \%$ of the norfloxacin treatment group and $93 \%$ of the chloramphenicol treatment group received clinical benefit from the treatment. In the evaluable patient population, $100 \%$ of the norfloxacin treatment group and $97 \%$ of the chloramphenicol treatment group received clinical benefit from study participation. Ninety-five per cent confidence intervals for cured, and cured or improved, are shown in Table II. Based upon the total number of patients enrolled,

Table III. Clinical outcome by organism (Evaluable patients)

\begin{tabular}{|c|c|c|c|c|c|c|c|c|}
\hline \multirow[b]{3}{*}{ Organism } & & \\
\hline & \multicolumn{4}{|c|}{$\begin{array}{l}\text { Norfloxacin } \\
\mathrm{C}^{1} \mathrm{I}^{2} \quad \mathrm{~N}^{3} \text { Total }\end{array}$} & \multicolumn{4}{|c|}{$\begin{array}{l}\text { Chloramphenicol } \\
\text { C I N Total }\end{array}$} \\
\hline & & & & & & & & \\
\hline Gram-negative & & & & & & & & \\
\hline Haemophilus sp. ${ }^{4}$ & 3 & & & 3 & 3 & & 0 & 4 \\
\hline Haemophilus influenzae & 3 & 0 & 0 & 3 & 2 & 1 & 0 & 3 \\
\hline Haemophilus parainfluenzae & 0 & 0 & 0 & 0 & 0 & 1 & 0 & 1 \\
\hline Gram-negative total & 6 & 0 & 0 & 6 & 5 & 3 & 0 & 8 \\
\hline Gram-positive organisms & & & & & & & & \\
\hline Staphylococcus aureus & 3 & 5 & 0 & 8 & 8 & 4 & 0 & 12 \\
\hline $\begin{array}{l}\text { Staphylococci, coagulase } \\
\text { negative }\end{array}$ & 4 & 2 & 0 & 6 & 5 & 0 & 0 & 5 \\
\hline Micrococcus sp. & 0 & 0 & 0 & 0 & 0 & 0 & 1 & 1 \\
\hline Streptococcus, $\alpha$-hemolytic & 1 & 1 & 0 & 2 & 1 & 0 & 0 & 1 \\
\hline Streptococcus, $\beta$-hemolytic & 0 & 0 & 0 & 0 & 2 & 0 & 0 & 2 \\
\hline Streptococcus pneumoniae & 10 & 8 & 0 & 18 & 5 & 5 & 0 & 10 \\
\hline Streptococcus Viridans group & 1 & 0 & 0 & 1 & 2 & 0 & 0 & 2 \\
\hline Gram-positive total & 191 & 16 & 0 & 35 & 23 & 9 & 1 & 33 \\
\hline Total & 251 & 16 & 0 & 41 & 281 & 12 & 1 & 41 \\
\hline
\end{tabular}

there was sufficient biostatistical power to detect a $20 \%$ difference in cure rates between the groups.

Shown in Table III is the clinical outcome, stratified by organism. All patients were judged as cured or improved, irrespective of organism. The observation of improvement or cure in all patients, irrespective of treatment group or organism precludes any differences between group, or organism or whether, indeed, the infection was bacterial.

Shown in Table IV is the bacteriological outcome, stratified by organism. The majority of all strains were erradicated or suppressed by each treatment, $83 \%$ by norfloxacin and $90 \%$ by chloramphenicol. The only exceptions were for one of eight and two of 12 isolates of Staphylococcus aureus and Streptococcus pneumoniae for norfloxacin, respectively and two of eight isolates of Haemophilus sp. for chloramphenicol.

Five patients were withdrawn from further study participation due to a presumed drug-related adverse experience. One norfloxacin-treated patient was withdrawn due to a mild burning upon instillation, and a second due to a mild headache. Two chloramphenicol-treated patients were withdrawn due to an ocular reaction, and one chloramphenicol-treated patient withdrawn due to eye pain.

\section{DISCUSSION}

We found norfloxacin to be effective and relatively safe for the treatment of presumed acute bacterial conjunctivitis and blepharoconjunctivitis. By both clinical and bacteriological criteria, norfloxacin was effective. Norfloxacin possessed a wide spectrum of activity in vivo and in vitro in this study, although Pseudomonas aeruginosa, against which norfloxacin has a good in vitro activity, did not occur. The patients treated with norfloxacin encompassed a wide age range. No severe or long-lasting adverse reactions were observed in the approximately one hundred patients treated with norfloxacin.

We observed norfloxacin to be of similar efficacy and

Table IV. Bacteriological outcome by organism (Evaluable patients)

\begin{tabular}{|c|c|c|c|c|c|c|c|c|}
\hline & \multicolumn{4}{|c|}{ Norfloxacin } & \multicolumn{4}{|c|}{ Chloramphenicol } \\
\hline & $E^{\prime}$ & & $\mathrm{P}^{3}$ & Total & $\mathrm{E}$ & S & $\mathrm{P}$ & Total \\
\hline \multicolumn{9}{|l|}{ Organism } \\
\hline \multicolumn{9}{|l|}{ Gram-negative } \\
\hline Haemophilus sp. ${ }^{4}$ & 3 & 0 & 0 & 3 & 3 & 0 & 1 & 4 \\
\hline Haemophilus influenzae & 3 & 0 & 0 & 3 & 2 & 0 & 1 & 3 \\
\hline Haemophilus parainfluenzae & 0 & 0 & 0 & 0 & 1 & 0 & 0 & 1 \\
\hline Gram-negative total & 6 & 0 & 0 & 6 & 6 & 0 & 2 & 8 \\
\hline \multicolumn{9}{|l|}{ Gram-positive organisms } \\
\hline Staphylococcus aureus & 6 & 1 & & 8 & 9 & 2 & 1 & 12 \\
\hline $\begin{array}{l}\text { Staphylococci, coagulase } \\
\text { negative }\end{array}$ & 5 & & 0 & 6 & 4 & 1 & 0 & 5 \\
\hline Micrococcus sp. & 0 & 0 & 0 & 0 & 1 & 0 & 0 & 1 \\
\hline Streptococcus, $\alpha$-hemolytic & 2 & 0 & 0 & 2 & 1 & 0 & 0 & 1 \\
\hline Streptococcus, $\beta$-hemolytic & 0 & 0 & 0 & 0 & 2 & 0 & 0 & 2 \\
\hline Streptococcus pneumoniae & 13 & 0 & 5 & 18 & 9 & 0 & 1 & 10 \\
\hline Streptococcus Viridans group & 1 & 0 & 0 & 1 & 2 & 0 & 0 & 2 \\
\hline Gram-positive total & 27 & 2 & 6 & 35 & 28 & 3 & 2 & 33 \\
\hline Total & 33 & 2 & 6 & 41 & 34 & 3 & 4 & 41 \\
\hline
\end{tabular}


safety to the established ocular antibacterial, chloramphenicol which is not effective for treating Pseudomonas infections. Our observations of the efficacy and relative safety of norfloxacin were similar to a large, well-controlled, American study comparing norfloxacin with tobramycin. ${ }^{13}$ The microbiological findings of this multicentre, international study were similar to those of the American study. Both the incidence of cultured organisms and their sensitivity to norfloxacin were similar in both studies.

The puzzling observation in the present study is the relatively low rate of positive cultures. The patients all had signs and symptoms typical of bacterial infections. Yet upon cultures, only one-third had significant growth of organisms to suggest a bacterial aetiology. The criteria used in this study for positive cultures were very rigorous. Only patients whose ocular samples produced growth significantly above background ${ }^{7}$ were considered to have positive cultures. If one considers all patients with bacterial growth from their ocular sample, then the positive culture rate was nearly two-thirds of the total population. One might conjecture that the techniques for sampling and culturing may have been biased towards a negative finding, although we have no direct test of this hypothesis. Yet a second conjecture is that the clinical appearance of bacterial infection, in some cases, is often false and due to a viral or chlamydial infection. Previous evaluations, either prospective or retrospective, have found that only $32-88 \%$ of patients with apparent external ocular bacterial infections have positive cultures. ${ }^{13-16}$ Another report suggests closer to $98 \%$ positive isolates, but employed a seven-day culture technique for anaerobic bacteria which involved culture of many colonising bacteria as well. ${ }^{17}$ Based upon the apparent self-limiting nature of this condition in some patients, one might be tempted to withhold treatment. However, the public health risks of individuals with purulent exudates which may be communicable, as well as the small but real threat of a sight-threatening complication, tend to outweigh the risks of treatment.

It is difficult to assess the natural history of presumed bacterial conjunctivitis in our study, as both groups of patients received active treatments. In a previously reported paediatric study, where some children did not receive antibacterial treatment, the disease was self-limiting, yet the severity and duration of the signs and symptoms of infection were less in the group receiving antibacterial treatment. ${ }^{18}$ While we cannot determine from this study the unequivocal efficacy of norfloxacin in treating external ocular bacterial infections, norfloxacin was similar to chloramphenicol in that the majority of patients in this study experienced clinical and microbiological resolution of their acute symptoms and signs.

In this study, norfloxacin was effective in controlling the observed bacteria. However, no patients in either treatment group had positive cultures for Pseudomonas, an organism of concern with respect to spectrum of antibacterial activity. Similary, no development of tolerance was observed in this study of large sample size, albeit of relatively short treatment duration. Finally, no significant, drug-related ocular or systemic adverse events were observed in either treatment group.

The authors wish to acknowledge the assistance of Gary D. Novack and Laura O'Grady in the preparation of this manuscript, and to thank David Seal for his helpful comments and guidance.

Key words: Antibacterial, Blepharoconjunctivitis, Chloramphenicol, Eye, Norfloxacin.

\section{REFERENCES}

1. Leopold IH: Review. Recent developments in chemotherapy of ocular diseases. J Ocular Pharmacol 1986, 2: 185-203.

2. Borrmann LR and Leopold IH: The potential use of quinolones in future ocular antimicrobial therapy. Am J Ophthalmol 1988, 106: 227-9.

3. Fernandes PB: Mode of action, and in vitro and in vivo activities of the fluroquinolones. J Clin Pharmacol 1988, 28: $156-68$.

4. Nix DE and Schentag JJ: The quinolones: An overview and comparative appraisal of their pharmacokinetics and pharmacodynamics. J Clin Pharmacol 1988, 28: 169-78.

5. Kestelyn P, Bogaerts J, Stevens AM, Piot P, Meheus A: Treatment of adult gonococcal keratoconjunctivitis with oral norfloxacin. Am J Ophthalmol 1989, 108: 516-23.

6. Osato MS, Jensen HG, Trousdale MD, et al.: The comparative in vitro activity of ofloxacin and selected ophthalmic antimicrobial agents against ocular bacterial isolates. Am J Ophthalmol 1989, 108: 380-6.

7. Cagle GD and Abshire RL: Quantitative ocular bacteriology: A method for enumeration and identification of bacteria from the skin-lash margin and conjunctiva. Invest Ophthalmol Vis Sci 1981, 20: 751-7.

8. Badiani D, Bron A, Elkington A, et al.: Use of a novel transport method for the quantification of the normal flora of the external eye. Microbiol Ecol Health Dis 1988, 1: 57-9.

9. Cagle G, Davis S, Rosenthal A, Smith J: Topical tobramycin and gentamicin sulfate in the treatment of ocular infections: A multicentre study. Curr Eye Res 1981, 1: 523-34.

10. Blyth CR and Still HA: Binomial confidence intervals. J Am Stat Assn 1983, 78: 108-16.

11. Mantel N: Chi-square tests with one degree of freedom: Extensions of the Mantel-Haenszel procedure. J Am Stat Assn 1963, 58: 690-700.

12. Fleiss JL: The design and analysis of clinical experiments. New York, John Wiley and Sons, 1986.

13. Jacobson JA, Call NB, Kasworm EM, Dirks MS, Turner RB: Safety and efficacy of topical norfloxacin versus tobramycin in the treatment of external ocular infections. Antimicrob Agents Chemother 1988, 32: 1820-4.

14. Jarudi N, Golden B, Hoyme J, Tyson MD, Harter JG: Comparison of antibiotic therapy in presumptive bacterial conjunctivitis. Am J Ophthalmol 1975, 79: 790-4.

15. Leibowitz HM, Pratt MV, Flastad IJ, Berrospi AR, Kundsin R: Human conjunctivitis: I. Diagnostic evaluation. Arch Ophthalmol 1976, 94: 1747-9.

16. The Trimethorpan-Polymixin B Sulphate Ophthalmic Study Group: Trimethorphan-polymyxin B sulphate ophthalmic ointment versus chloramphenicol ophthalmic ointment in the treatment of bacterial conjunctivitis: A review of four clinical studies. J Antimicrobial Chemotherapy 1989, 23: 261-6.

17. Perkins RE, Kundsin RB, Pratt MV, Abrahamsen I, Leibowitz HM: Bacteriology of normal and infected conjunctiva. J Clin Microbiol 1975, 1: 147-9.

18. Gigliotti F, Hendley JO, Morgan J, Michaels R, Dickens M, Lohr J: Efficacy of topical antibiotic therapy in acute conjunctivitis in children. J Pediatrics 1984, 104: 623-6. 